\title{
Aggression Scale
}

National Cancer Institute

\section{Source}

National Cancer Institute. Aggression Scale. NCI Thesaurus. Code C121292.

A rating scale included in the Behavior Assessment System for Children that measures the tendency of the subject to act in a hostile manner, either verbally or physically, that is threatening to others. 